\title{
Further evidence on the extent and time course of repeat missing incidents involving children: $A$ research note
}

The Police Journal:

Theory, Practice and Principles 202I, Vol. 0(0) I-II

(C) The Author(s) 2021

\section{(c) (i)}

Article reuse guidelines: sagepub.com/journals-permissions DOI: 10.1 I 77/0032258X21 1052900 journals.sagepub.com/home/pjx

@SAGE

\section{Clara Galiano López \\ University College London, London, UK}

\section{Jane Hunter}

Missing People, London, UK

\section{Toby Davies and Aiden Sidebottom}

University College London, London, UK

\begin{abstract}
This study examines the extent and time course of repeat missing incidents involving children. Using data from one UK police force $(n=2,25 \mathrm{I})$, we find $(\mathrm{I})$ that the majority $(65 \%)$ of missing incidents are repeats, (2) that a small group of repeatedly missing children ( $n=43 ; 6 \%)$ account for a sizable proportion of all missing incidents $(n=739$, $33 \%$ ) and (3) that the likelihood of a child going missing repeatedly is elevated in the weeks immediately following a previous missing incident. The implications of our findings for future research and for the prevention of missing incidents are discussed.
\end{abstract}

\section{Keywords}

Children, missing, police, repeat

\section{Introduction}

Someone is reported missing on average every 2 minutes in England and Wales (National Crime Agency, 2021). Latest figures show that in 2019/20, there were 325,171 police recorded missing person incidents, an increase of 34\% from 2015/16 (National Crime

Corresponding author:

Aiden Sidebottom, University College London, 35 Tavistock Square, London WCIE 6BT, UK.

Email: a.sidebottom@ucl.ac.uk 
Agency, 2021). Responding to reports of missing persons is a major source of demand on the police service (The Police Foundation, 2020), estimated to cost upward of $£ 500$ million per year (Babuta and Sidebottom, 2020) and account for over three million police 'investigation hours' (College of Policing, 2015). Determining the appropriate response to each missing incident is a complex and challenging task (see Tarling and Burrows, 2004). The term 'missing person' encompasses a diverse group of people who go missing for a variety reasons, many of whom exhibit underlying vulnerabilities to do with age, mental health and substance dependencies. Moreover, although the majority of missing persons return safe, swiftly and without the need for police intervention (Fyfe et al., 2015), a small proportion of individuals are exposed to harm (broadly defined) when missing (Doyle and Barnes, 2020; Rees and Lee, 2005). In 2019/20 in England and Wales, there were 955 cases in which an individual reported as missing was later found deceased (National Crime Agency, 2021).

Children and young people make up the majority of missing person incidents (National Crime Agency, 2021). They go missing for a variety of reasons, be it 'intentional' (e.g. a child deciding to run away), 'unintentional' (e.g. a child being separated from their parents) or 'forced' (e.g. a child being abducted) (Biehal et al., 2003). According to recent estimates from England and Wales (National Crime Agency, 2021), common reasons given for why children go missing (in descending order) include relationship issues (18\%) (i.e. being unhappy where they are living), mental health (16\%) and drugs or alcohol $(13 \%)$.

In recent years, there has been increased political, police and public attention paid to the subject of missing children and young people. In 2017, for example, an All Party Parliamentary Group convened a roundtable discussion to better understand the risks faced by children who go missing. This gathering was partly in response to a growing body of evidence linking child disappearances to an increased risk of sexual exploitation (Cockbain et al., 2015; Scott and Skidmore, 2006), health-related harms (Whitbeck et al., 2007), involvement in crime (Heerde et al., 2014; Shalev, 2011) and criminal exploitation $^{1}$ (National Crime Agency, 2017; The Children's Society, 2018). In addition, concerns have been raised about the unnecessary criminalisation of children who come into contact with the police through being reported missing (Howard League, 2017), particularly children in care placements who are over-represented in missing persons data (Babuta and Sidebottom, 2020; Department for Education, 2021; Hayden 2017; Hayden and Shalev Greene 2018; Sidebottom et al., 2020) and whom may not consider themselves missing (Missing People, 2021).

It is well-established that some children are reported missing repeatedly and that children and young people are more likely to go missing repeatedly than are adults (Biehal et al., 2003). As outlined by Hayden and Shalev-Greene (2018), repeat missing episodes are often interpreted as evidence of some underlying issue in a child's life. In a recent study from Wales, Hutchings et al. (2019) found that children who went missing repeatedly were more likely to have a history of child abuse and neglect, exhibit substance abuse issues, be linked to possible child sexual exploitation, be known to youth offending services and be looked after by the local authority. Using data from a 10-year follow-up study in Australia, Stevenson and Thomas (2018) similarly found that individuals who 
went missing repeatedly were more likely (than one-time only missing persons) to exhibit mental-health related vulnerabilities and report a greater involvement in crime (see also Shalev, 2011).

Despite a general awareness of the high frequency of repeat missing incidents involving children, research into the prevalence and concentration of repeat missing incidents is sparse. Two recent exceptions are Babuta and Sidebottom (2020) and Sidebottom et al. (2020). Babuta and Sidebottom (2020) used data on all missing incidents involving children from one police force in England and Wales for the period January 2011-May $2013(n=1885)$. They found that (1) a small percentage of missing children (5\% of the sample) accounted for almost a third of all police recorded child disappearances $(n=573)$ and (2) that those children who went missing repeatedly were more likely to be teenagers, reside in care and have a history of family conflict. In a follow-up study using 12 months of data from a different police force area, Sidebottom et al. (2020) reported similarly high levels of concentration, such that $4 \%(n=59)$ of children who went missing 10 times or more accounted for $28 \%$ of all missing incidents involving children $(n=952)$, generating an estimated police cost of $£ 2.29$ million. ${ }^{2}$ Repeatedly missing children were also found to be significantly more likely to be teenagers, reside in care and exhibit drug and/or alcohol dependencies. Extending previous studies, Sidebottom et al. (2020) also showed that the number of weeks between a child returning from an initial missing incident and them being reported missing again was relatively short, with over half of all first repeats taking place within 4 weeks. ${ }^{3}$

This brief article is a partial replication and extension of Sidebottom et al. (2020). Using data from a different police force area, it reports the findings of analysis into the extent and time course of repeat missing incidents involving children. In anticipation of the results to follow, we present additional evidence in support of the hypothesis that a substantial number of missing episodes are attributable to a small number of repeatedly missing children. If generalisable, we believe this finding has important implications for the police and partners responsible for the protection and safeguarding of young people and more specifically the development and targeting of interventions designed to reduce the incidence of and risks associated with repeat missing episodes involving children.

\section{Data}

Data were made available on all missing incidents involving children (aged 17 and under) recorded by one predominately rural police force in the South of England for the period April 2017 to March 2018. Each missing incident contained a unique anonymised person identifier, the child's age and gender, their legal status at the time they went missing (e.g. whether a child was looked after in the care system; whether a child was known to child services), the date and time the child was reported missing, the date and time the child returned or was found (where appropriate) and the outcome of a police risk assessment. ${ }^{4}$ From the information provided, three additional variables were computed: (1) the number of hours a child was missing per missing incident, (2) the number of missing incidents per child over the 12-month study period and (3) the time elapsed between missing episodes for those individuals reported missing more than once. 
It warrants mention here that unlike previous similar studies, we did not have access to information on the locations from which children were reported to have gone missing nor the risk factors associated with each missing incident, such as whether a missing person had a history of substance abuse, family conflict and so on. These variables are often used in statistical analyses to determine the correlates of repeat disappearances (see for, e.g. Babuta and Sidebottom, 2020; Huey et al., 2020; Hutchings et al., 2019; Sidebottom et al., 2020). Such analyses were therefore not possible with the data used here.

A small number of incidents were removed prior to analysis $(n=184)$. These omissions related mainly to incidents that fell outside the scope of this study (e.g. missing adults) and recording errors (e.g. when a person was recorded as being found on a date that preceded the date they were recorded as missing). Our final sample contained 2251 police recorded missing incidents involving 781 unique individuals aged 17 or under.

\section{Results}

\section{Descriptive statistics}

Table 1 presents descriptive statistics for the individuals and incidents in our dataset. Following Sidebottom et al. (2020), individuals were divided into three groups based on the number of reported missing incidents over the 1-year study period: those reported missing once, those reported missing on two-to-nine occasions and those reported missing 10 times or more. Our findings show little variation in the age of individuals who are reported missing at different frequencies $(\mathrm{F}(2,778)=.362, p=.696)$. By contrast, we find a statistically significant relationship between the frequency of missing episodes and

Table I. Individual $(n=78 \mathrm{I})$ and incident $(n=225 \mathrm{I})$ characteristics for a sample of missing children reports.

\begin{tabular}{lllll}
\hline Characteristics & Full sample & Missing once & $\begin{array}{l}\text { Missing two to } \\
\text { nine times }\end{array}$ & $\begin{array}{l}\text { Missing I0 times } \\
\text { or more }\end{array}$ \\
\hline Individuals & $(n=78 \mathrm{I})$ & $(n=437)$ & $(n=30 \mathrm{I})$ & $(n=43)$ \\
Age (mean) & 14.4 & 14.4 & 14.3 & 14.3 \\
Gender (\% male) & 46.9 & 49.7 & 45.9 & 25.6 \\
Looked after child (\%) & 34.1 & 27.0 & 41.9 & 51.2 \\
Incidents & $(n=225 \mathrm{I})$ & $(n=437)$ & $(n=1075)$ & $(n=739)$ \\
\% Assessed as high risk & 3 & 7 & 3 & 3 \\
Hours missing (median) & $2 \mathrm{I}$ & 18 & 23 & 22 \\
Returned <24 h (\%) & 55.2 & 62.0 & 52.7 & 54.8 \\
Returned >24 but <48 h (\%) & 26.4 & 20.6 & 27.3 & 28.4 \\
Returned > 48h <l week (\%) & 15.2 & 12.1 & 16.2 & 15.7 \\
Returned > I week (\%) & 3.2 & 5.3 & 3.8 & 1.1 \\
\hline
\end{tabular}

aDenoting those entries marked as: 'looked after child' and 'out of area looked after child'.

'This relates to 1487 incidents; in a third of incidents, no risk assessment outcome was contained in the data. The reasons for this are unknown. 
gender $\left(X^{2}(2, n=781)=9.3, p<.05\right)$ and being in care $\left(X^{2}(2, n=781)=23.4, p<.001\right)$, with females accounting for $74 \%$ and children in care placements accounting for $51 \%$ of children reported missing 10 times or more, respectively. Consistent with previous findings (National Crime Agency, 2021; Sidebottom et al., 2020), in the majority of cases, the missing person was found or returned within 2 days of being reported missing. Incidents in which the child or young person was missing for over 1 week were proportionally more frequent among those missing once compared to those reported missing repeatedly, albeit still rare. Related to this, the proportion of police-assessed high-risk missing incidents was higher in cases where the person was reported missing only once. This may be a function of previous missing incidents affecting the risk assessment of subsequent missing incidents.

\section{Repeat missing incidents}

Table 2 displays the frequency of missing incidents involving children. It shows that just over half of the children in our dataset went missing once during the 12 month study period ( $n=437,56.0 \%$ ). Although these one-time only missing children make up the majority of individuals in our dataset, collectively they account for only a fifth of all missing incidents $(19.4 \%)$, thereby indicating the presence of repeat disappearances. Thus, approximately $80 \%$ of missing incidents related to children who went missing more than once over the 12 month study period; or, put differently, $65 \%$ of missing incidents were repeats. ${ }^{5}$ Consistent with previous research (Babuta and Sidebottom, 2020; Sidebottom et al., 2020), we find a high concentration of missing incidents among a small proportion of repeatedly missing children. More precisely, children who were reported missing 10 times or more made-up six percent of all missing children $(n=43)$ but collectively accounted for a third of all missing incidents $(n=739)$.

Table 2. Missing incidents involving children and young people, April 2017 and March 2018 (inclusive).

\begin{tabular}{lll}
\hline Number of missing incidents & Number (\%) of children & Number (\%) of incidents \\
\hline 1 & $437(56.0)$ & $437(19.4)$ \\
2 & $124(15.9)$ & $248(11.0)$ \\
3 & $65(8.3)$ & $195(8.7)$ \\
4 & $34(4.4)$ & $136(6.0)$ \\
5 & $30(3.8)$ & $150(6.7)$ \\
6 & $20(2.6)$ & $120(5.3)$ \\
7 & $9(1.2)$ & $63(2.8)$ \\
8 & $8(1.0)$ & $64(2.8)$ \\
9 & $11(1.4)$ & $99(4.4)$ \\
10 or more & $43(5.5)$ & $739(32.8)$ \\
Total & $781(100)$ & $2251(100)$ \\
\hline
\end{tabular}




\section{Time course of repeat missing incidents involving children}

Our final area of analysis considers the time elapsed between missing incidents involving the same young person. Our interest is to determine whether children who have gone missing and returned are then more likely to be reported missing again for some period afterwards - so-called 'event dependence'. Furthermore, if such a dependence does exist, we aim to identify the time period over which the elevated probability of going missing extends.

To investigate event dependence in our data, we first produced two histograms showing the distribution of time intervals between individuals' missing episodes (see Figure 1). It is apparent that pairs of missing episodes tend to occur close together: the cumulative histogram indicates that $66 \%$ of repeat missing incidents occur within 4 weeks of the child's previous missing episode, for example. These patterns are suggestive of event dependence, as was the case in Sidebottom et al. (2020). However, these patterns alone do not provide conclusive evidence of such an effect: a bias towards short interevent times would be expected even if the timing of missing episodes was purely random, and so a relationship such as this is not evidence of any event-dependence effect. To test for this and improving on the methods used in Sidebottom et al. (2020), we instead adopt an approach introduced by Short et al. (2009) to test for event-dependence in crime data.

In brief, the approach - named the Fixed Window Method - involves observing events over a fixed temporal window (in this case, 1 year) and identifying all units of analysis which experienced a given number of incidents within that window (in this case, 2). The times between events for all such units are calculated and plotted as a histogram and then compared against the distribution of intervals that would be expected if the timings of events (here missing incidents) were random. Crucially, this distribution is known

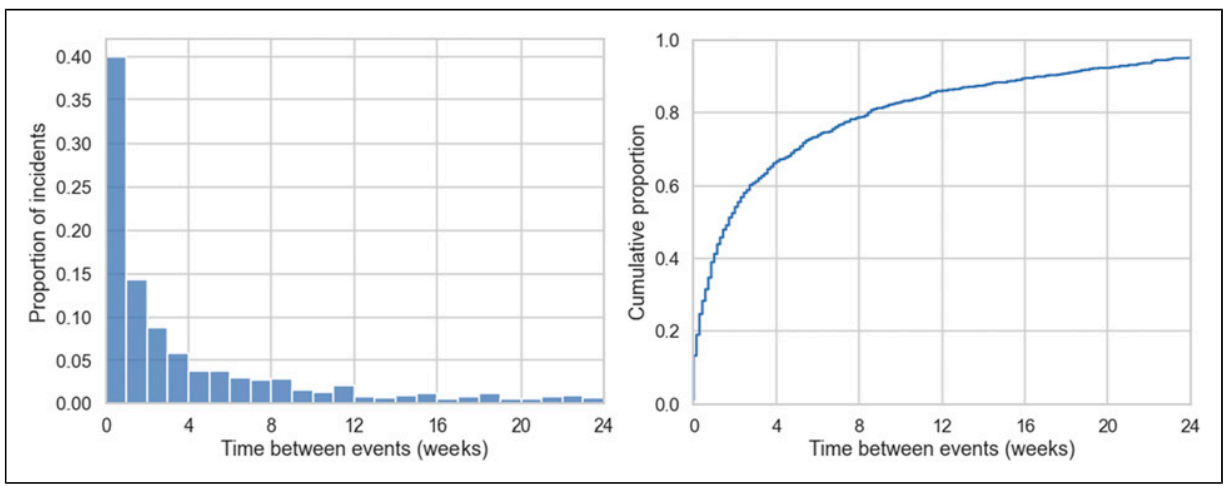

Figure I. Histogram and cumulative histogram displaying the time course of repeat missing incidents involving children and young people, April 2017 and March 2018 (inclusive). Only pairs of incidents in which the first occurred more than 24 weeks prior to the end of the study window are included, in order that any repeat incidents occurring within 24 weeks are guaranteed to be present in the data. 
exactly: if events happened randomly, they would be equally likely to happen on each day, and so the expected intervals can be calculated straightforwardly.

In Figure 2, we show the results of this analysis for the present data. The histogram shows the inter-event intervals, while the solid black line shows the shape this would be expected to follow if the timings of events were random. The over-representation of short intervals (and corresponding under-representation of longer ones) is strong evidence that event-dependence is present in the missing episodes analysed here. In other words, missing episodes for a given individual occur closer together than they would be expected to if there was no association between them.

\section{Discussion}

This study investigated the extent and time course of repeat missing incidents involving children. We found that repeat missing incidents were (1) highly prevalent, accounting for nearly two-thirds of all missing incidents involving children; (2) highly concentrated, such that a small proportion of repeatedly missing children $(6 \%)$ accounted for almost a third of all missing incidents and (3) event-dependent, with the likelihood of a child being reported missing on a subsequent occasion elevated in the 4 weeks following an initial disappearance.

Replication is a cornerstone of science. It is therefore noteworthy that the concentration patterns observed here closely resemble those found in previous research (Babuta and Sidebottom, 2020; Sidebottom et al., 2020). This is clearly apparent in Figure 3, in which Lorenz curves display the cumulative proportions of missing incidents against the

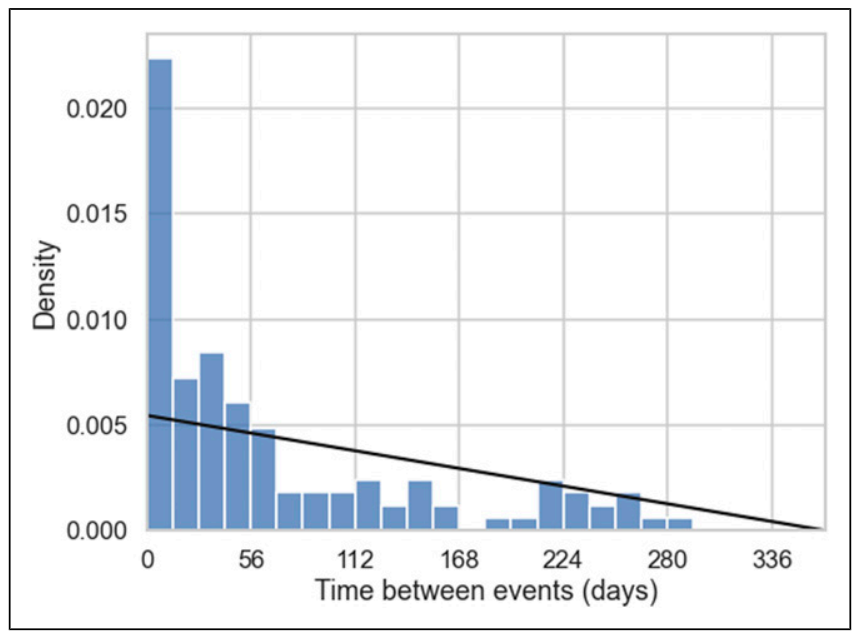

Figure 2. Inter-event intervals for all individuals who went missing exactly 2 times during the I-year study period, as per the Fixed Window Method. The black line shows the distribution that would be expected if the timings of events were random. Note that in this case the inter-event times are calculated as the time between the start of one episode and the start of the next. 


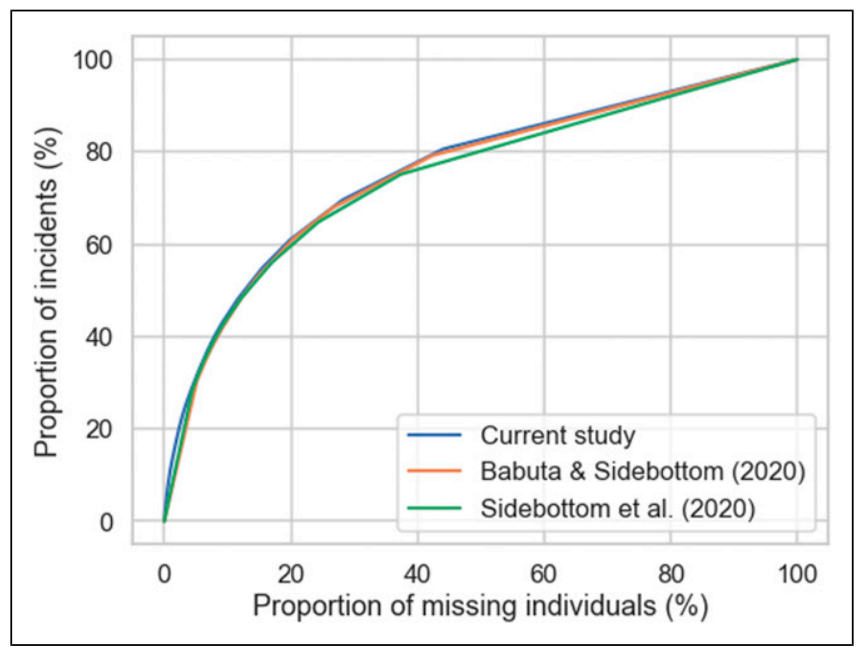

Figure 3. A comparison of three Lorenz curves generated from police missing persons data from three studies on the cumulative proportion of missing incidents by the proportion of missing children.

proportion of missing children across three comparable studies. It can be seen that there is a remarkably high degree of consistency across the three studies, despite them covering different police force areas over different time periods. In each case, Figure 3 reveals that around $20 \%$ of repeatedly missing children accounted for around $60 \%$ of all missing incidents involving children. If confirmed elsewhere, this finding holds important implications for the prevention of and police and partner response to missing incidents involving children. At its simplest, the pattern suggests that a prevention strategy directed at those who go missing repeatedly promises to yield substantial reductions in the number of missing incidents overall.

Knowing where to direct preventive resources tells us little about when those resources might be put to best use. Our analysis on the time course of repeat missing incidents is thus informative, particularly the finding that two-thirds of repeat missing incidents occurred within 4 weeks of a child returning from a previous missing episode. If generalisable, this pattern highlights the importance of timely interventions intended to prevent subsequent missing episodes. In practice, of course, this is difficult to achieve, as is seen in the case of return home interviews which should be offered as standard in England within 72 hours of a young person returning from a missing episode. One of the express purposes of return home interviews is to 'uncover information that can help protect children from the risk of going missing again' (Department for Education, 2014: 14; italics added by authors). However, as identified by Pona et al. (2019), there are several recurrent difficulties in meeting the 72-hour deadline for return home interviews.

As indicated above, a major limitation in this study is the lack of information made available for analysis, most notably information on the locations whence a child went missing and the risks associated with each missing incident (e.g. whether the missing 
child had any known mental health problems, substance dependency and so on). Absent this information, we could not adequately determine the correlates of repeat missing incidents nor could we assess the relationship between repeat missing people and places. The latter is noteworthy given previous research from Canada (Huey et al., 2020) and England and Wales (Hayden and Shalev Greene, 2018) finds that a small number of locations generate a sizable proportion of all missing incidents. Finally, the analyses presented here are largely exploratory and descriptive. We were unable with the data at hand to deduce evidence on the mechanisms that might plausibly account for the observed patterns of repeat missing incidents. This is an area to which future research might fruitfully be directed, likely drawing on a range of data sources to better understand the circumstances and nature of missing incidents.

\section{Declaration of conflicting interests}

The author(s) declared no potential conflicts of interest with respect to the research, authorship, and/ or publication of this article.

\section{Funding}

The author(s) received no financial support for the research, authorship, and/or publication of this article.

\section{ORCID iD}

Aiden Sidebottom (D) https://orcid.org/0000-0003-0534-2715

\section{Notes}

1. Criminal exploitation is often referred to as 'county lines', denoting the practice of gangs or organised crime groups using young people and vulnerable adults in the distribution, storage and sale of drugs across county borders.

2. Computed using cost estimates reported in Shalev-Greene and Pakes (2014).

3. It should be noted that research into the time course of repeat missing incidents was inspired by and uses the same approach as research into the time course of repeat victimisation (see e.g. Polvi et al., 1991).

4. All missing incidents are subject to a police risk assessment based on the information available at the time. The speed and intensity of the police response to a missing incident is determined by the outcome of the risk assessment. There are four main outcomes of a police risk assessment: 'absent', 'low risk', 'medium risk' and 'high risk'. The 'absent' category was not used by the police force in this study and was therefore excluded from analysis. An incident categorised as low risk are those where the risk of harm to the individual or public is deemed to be minimal and therefore only a basic police response is required. A medium risk incident refers to cases where the risk of harm to the individual or public is judged to be likely but not serious, therefore requiring an active and measured police response. Lastly, high risk incidents are those in which it is considered that there is very likely risk of serious harm (to life and/or well-being) to the 
individual or public, and hence, an immediate deployment of police resources is necessary. For a general discussion of risk assessment in the context of missing persons, see Eales (2017).

5. To elaborate, for each person who goes missing multiple times, their first episode is not a repeat (within the study period, at least). So the number of actual repeats in the dataset is $2251-781=$ 1470 (there are 781 individuals in the dataset, and each of them has exactly one 'first'), and hence, the proportion of repeat missing incidents is $1470 / 2251$.

\section{References}

Babuta A and Sidebottom A (2020) Missing children: on the extent, patterns, and correlates of repeat disappearances by young people. Policing: A Journal of Policy and Practice 14(3): 698-711.

Biehal N Mitchell F and Wade J (2003) Lost from View: Missing Persons in the UK. Bristol: Policy Press.

Cockbain E, Ashby M and Brayley H (2015) Immaterial boys? A large-scale exploration of genderbased differences in child sexual exploitation service users. Sexual Abuse 29(7): 658-684.

College of Policing (2015) College of policing analysis: estimating demand on the police service. Available from: http://www.college.police.uk/News/College-news/Documents/demand\% 20Report\%2023_1_15_noBleed.pdf

Department for Education (2014) Statutory Guidance on Children Who Run Away or Go Missing from Home or Care. London: Department for Education.

Department for Education (2021) Children looked after in England including adoptions. Available online at: https://explore-education-statistics.service.gov.uk/find-statistics/children-lookedafter-in-england-including-adoptions/2020

Doyle R and Barnes GC (2020) Targeting missing persons most likely to come to harm among 92,681 cases reported to Devon and Cornwall Police. Cambridge Journal of Evidence-Based Policing 4(3): 160-177.

Eales N (2017) Risk assessment. In: Shalev-Greene K and Alys L (eds), Missing Persons: A Handbook of Research. New York, NY: Taylor \& Francis.

Fyfe NR, Stevenson O and Woolnough P (2015) Missing persons: the processes and challenges of police investigation. Policing and Society 25(4): 409-425.

Hayden C (2017) Children missing from care. In: Shalev-Greene K and Alys L (eds), Missing persons: A Handbook of research. New York, NY: Taylor \& Francis.

Hayden C and Shalev-Greene K (2018) The blue light social services? Responding to repeat reports to the police of people missing from institutional locations. Policing and Society 28(1): 45-61.

Heerde JA, Hemphill SA and Scholes-Balog KE (2014) 'Fighting' for survival: a systematic review of physically violent behavior perpetrated and experienced by homeless young people. Aggression and Violent Behavior 19(1): 50-66.

Howard, League (2017) Ending the criminalisation of children in residential care. Available online at: https://howardleague.org/publications/ending-the-criminalisation-of-childrenin-residential-care/

Huey L, Ferguson L and Kowalski L (2020) The “power few” of missing persons' cases. Policing: An International Journal 43(2): 360-374.

Hutchings E, Browne KD, Chou S, et al. (2019) Repeat missing child reports in Wales. Child Abuse and Neglect 88: 107-117. 
Missing People (2021) Children's views on being reported missing from care. Available online at: https://www.missingpeople.org.uk/wp-content/uploads/2021/04/Childrens_views_on_being_ reported_missing_from_care.pdf

National Crime Agency (2017) County Lines Violence, Exploitation \& Drug Supply. London: NCA.

National Crime Agency (2021) Missing Persons Data Report 2019/20. UK Missing Persons. National Crime Agency.

Polvi N, Looman T, Humphries C, et al. (1991) The time course of repeat burglary victimization. The British Journal of Criminology 31(4): 411-414.

Pona I, Raws P and Chetwynd H (2019) The First Step: How Return Home Interviews Can Improve Support and Safeguarding for Missing Young People. London, NPCC: The Children's Society.

Rees G and Lees J (2005) Still Running II: Findings from the Second National Survey of Young Runaways. London: The Children's Society.

Scott S and Skidmore P (2006) Reducing the Risk: Barnardo's Support for Sexually Exploited Young People. A Two-Year Evaluation. London: Barnardo's.

Shalev K (2011) Children who go missing repeatedly and their involvement in crime. International Journal of Police Science and Management 13(1): 29-36.

Shalev Greene K and Pakes F (2014) The cost of missing person investigations: implications for current debates. Policing 8(1): 27-34.

Short MB, D’Orsogna MR, Brantingham PJ, et al. (2009) Measuring and modeling repeat and nearrepeat burglary effects. Journal of Quantitative Criminology 25(3): 325-339.

Sidebottom A, Boulton L, Cockbain E, et al. (2020) Missing children: risks, repeats and responses. Policing and Society 30(10): 1157-1170.

Stevenson E and Thomas SDM (2018) A 10 year follow-up study of young people reported missing to the police for the first time in 2005. Journal of Youth Studies 21(10): 1361-1375.

Tarling R and Burrows J (2004) The nature and outcome of going missing: the challenge of developing effective risk assessment procedures. International Journal of Police Science and Management 6(1): 16-26.

The Children's Society (2018) Children and young people trafficked for the purpose of criminal exploitation in relation to county lines. A toolkit for professionals. Available online at: https:// www.childrenssociety.org.uk/sites/default/files/2021-01/exploitation-toolkit.pdf.

The Police Foundation (2020) Public Safety and Security in the 21st Century. The First Report of the Strategic Review of Policing in England and Wales. Available online at: https://www. policingreview.org.uk/wp-content/uploads/phase_1_report_final-1.pdf.

Whitbeck LB, Hoyt DR, Johnson KD, et al. (2007) Victimization and posttraumatic stress disorder among runaway and homeless adolescents. Violence and Victims 22(6): 721-734. 